\title{
Uma questão ainda sem resposta: O que é a Educação Fisica?
}

Lamartine P. da Costa

A nossa revista Movimento, em seus dois primeiros números editados em 1994 e 1995, publicou, por separatas em páginas centrais, um conjunto de contribuições que se desenvolveu em torno de uma questão clássica e instigante: "Afinal, o que é a Educação Física?"

Por um mapeamento epistemológico, Adroaldo Gaya, da UFRGS, inicia a seqüência de ensaios adotando um ponto de vista cético quanto à Educação Física como uma disciplina científica ou quanto à sua redução a pressupostos filosóficos. Após revisar fontes diversificadas que identificam o conhecimento em questão com o lazer, filosofia da corporeidade, saúde, motricidade humana e o u tros te m a s e manifestações, Gaya argumenta que, tanto como ciência quanto como filosofia, há dissolução do significado social e profissional da Educação Física. A solução residiria, então, em interpretá-la como "disciplina normativa que se concretiza através de uma prática pedagógica com objetivos formativos".

Enquanto tal, o projeto pedagógico defendido por

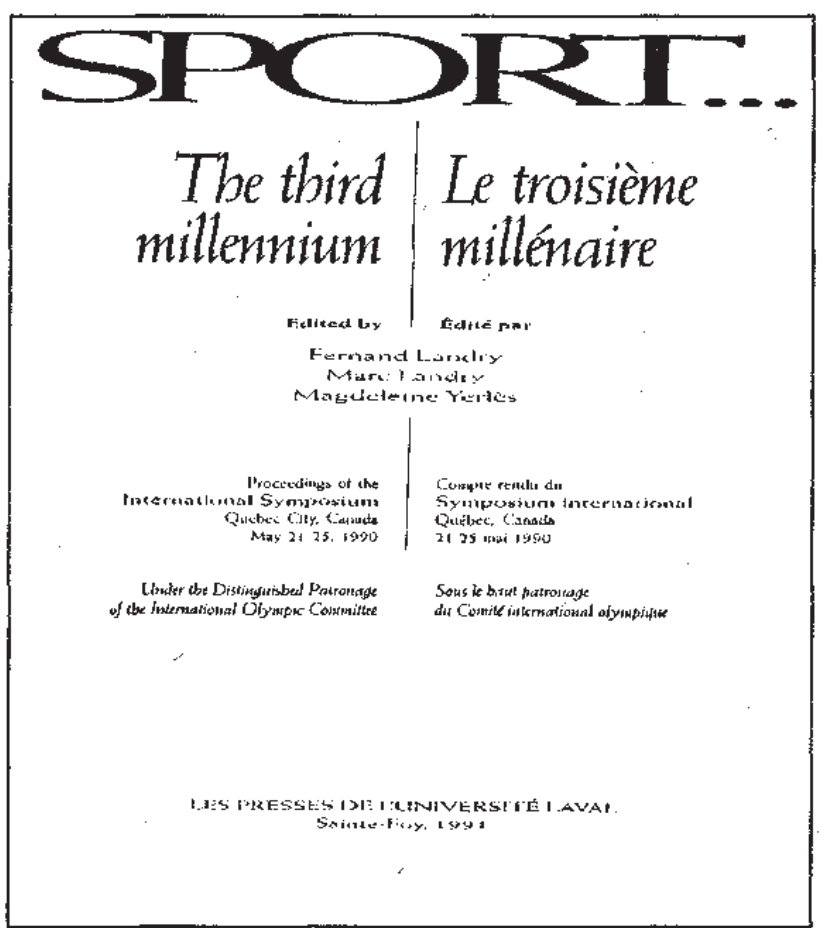

Gaya pressupõe, todavia, uma fundamentação axiológica, como também uma "validação de conteúdos e conhecimentos capazes de estruturar técnicas de efetiva i ntervenção" qu e informariam o agente pedagógico, isto é, o professor de Educação Física. Mas essa pretensão não é compartilhada por Celi Taffarel e Micheli Escobar, autoras do segundo texto da coletânea, que se contrapõem à visão de três dimensões relacionadas à Educação Física definidas por Gaya: epistemologia, axiologia e pedagogia.
D e $\quad \mathrm{mod} o$ contundente, as duas professoras citadas, pertencentes aos quadros da UFPE, criticam inicialmente Gaya por suas "concepções idealistas" e seu "simplismo intelectual", uma vez que ele "demonstra desconhecer, ou relega por escolha pessoal, a teoria dialética materialista histórica da produção e apropriação social do conhecimento". Nesse viés de reabilitação marxista, o fio condutor da análise do texto original é naturalmente o das relações de produção, como indicam textualmente as autoras: 
"... argumentações como as de Gaya e dos autores que ele analisa de forma simplista explicam-se pela não consideração da Educação Física como produção não material que, em determinados estágios e pela influência de certos fatores próprios do sistema capitalista, sofre o mesmo processo de privação das qualidades sensíveis sofrido pela produção material".

Negada a tese da produção de relações de ensino-aprendizagem, encontrada no texto originário da controvérsia, ao se lhe antepor o princípio historicista das relações de produção do sistema capitalista, Taffarel e Escobar passam a vincular o pretenso equívoco de Gaya à legitimação de "uma perspectiva filo-

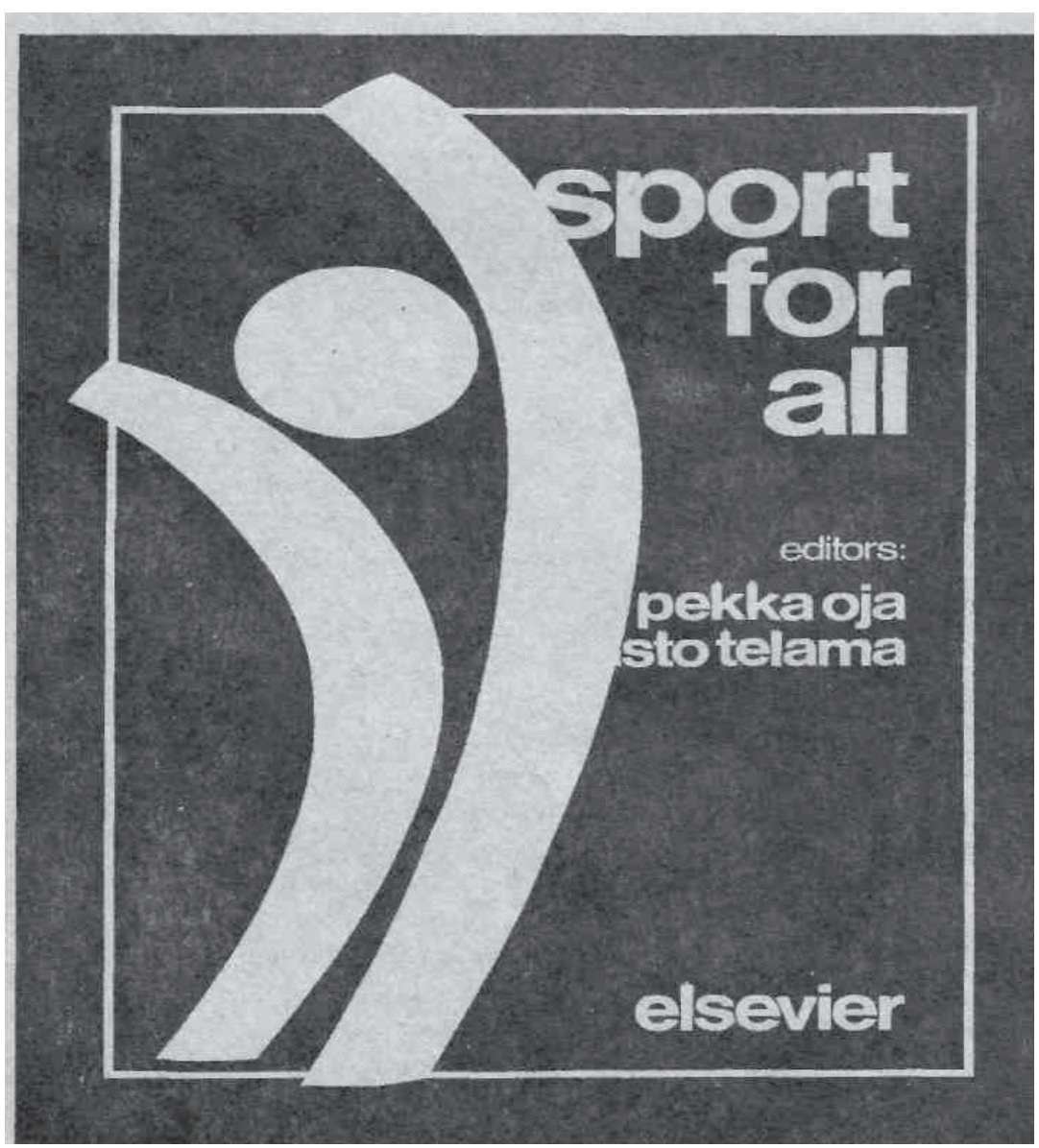

sófico-científica superada, esgotada, que é o idealismo e o método empírico-analítico de pesquisa". Com maior agressividade, a crítica termina lamentando que os brasileiros estudantes na Europa e nos Estados Unidos nem sempre reconheçam as "sucatas científicas idealistas" a eles oferecidas, sugerindo ser essa a postura de Gaya que faz seu doutoramento em Portugal ao invocar 44 autores nacionais e estrangeiros em seu artigo.

"Já a contribuição seguinte, a de Walter Bracht, da UFES, tenta colocar o debate nos seus devidos eixos, reexaminando o sentido da pergunta inicial, e p o s i c i o n a n d o a terminologia, reabilitando a perquirição filosófica sobre o problema epistemológico adiantado por Gaya e, sobretudo, levantando a possibilidade da polêmica instalada entre as duas primeiras contribuições ser essencialmente referida ao embate entre teoria e prática ("não resolvido nem na teoria nem na prática"). Buscando uma saída acadêmica para as duas posições em confronto, Bracht incursiona com desenvoltura pela problemática da razão uma questão esclarecedora das incertezas geradas pelas afirmativas científicas e pelos dogmas ideológicos de nossos dias assumindo um tom habermasi-ano ao procurar soluções por meio de "um conceito de razão que permita a mediação entre essas diferentes dimensões da racionalidade humana".

A pó $\mathrm{s}$ e $\mathrm{s} s$ a reconstrução, Bracht progride pela senda da crítica à racionalidade e aborda a rejeição às postu-lações de Gaya apelando para Apel, em citação de 1988, que tentara uma resposta à fragmentação da razão no marco teórico do marxis mo-len in is mo ortodoxo. Em resumo, para aquele pensador alemão, o tema das racionalidades contraditórias concerne ao abismo entre ser e dever ser, cuja transposição - ou melhor, quando se pergunta sobre o que devemos fazer depende da "percepção daqueles que dispõem do saber dialético sobre o curso necessário da história".

Em vista dessa proposição, Bracht conclui com elegância:

\footnotetext{
"Gaya interpreta a pergunta $O$ que é a Educação Física? em dois sentidos. Primeiro quanto à definiç̧ão (que é sempre deli-
} 
mitação/demarcação) de um objeto: Educação Física é uma prática pedagógica, portanto normativa; segundo, como definir a especificidade dessa prática em relação à filosofia $\mathrm{e}$ à ciência (num percurso entre a filosofia e a ciência). Pareceme que Taffarel e Escobar interpretam a mesma pergunta de outra forma, levantando expectativas que vão muito além das colocadas por Gaya para esse momento. Por isso, minha observação inicial na qual afirmei que o debate mesmo não pôde acontecer".

C o m ín d o 1 e acadêmica idêntica a de Bracht, apresenta-se a seguir Silvino Santin, da UFRGS, outro debatedor que prefere apreciar a questão originária da Educação Física a partir de fundamentos. A pós digressões e esclarecimentos vários, Santin dá continuação à tarefa civilizatória de Bracht, concluindo igualmente sobre os planos diferentes de análise, ao comparar o trabalho de Gaya com a crítica de Taffarel e Escobar:

"Finalmente, volto a insistir que estamos diante de dois textos com arquitetura distintas. Um, inspirando-se no modo de pensar da metafísica, procura a essência de uma ação; outro, baseado no pensamento marxista e reformado pela Escola de Frankfurt, sustenta a tese de que todo saber e toda ação devem ser vistas a partir de sua vinculação social. Tais diversidades arquitetônicas do pensamento, além de enriquecerem a reflexão, têm o mérito de identificar os lugares ideológicos a partir dos quais todos e cada um costumam falar".
Com a retomada do que

julgo essencial dos textos

do intencionado debate e

respondendo a um convite

dos editores da revista

Movimento, pretendo,

neste ensaio, desentravar a

polêmica criando posições

que tragam à luz novas

contribuições.

Paulo Guiraldelli (UNESP), autor do quinto texto, prefere não confrontar os dois primeiros trabalhos, deslocando o sentido polêmico da pergunta $O$ que é a Educação Física? para uma breve análise sobre as posições de Gaya. Nessas circunstâncias, Guiraldelli vê em Gaya um continuador da tradição pragmática de Dewey:

"O pragmatismo americano confere valor de verdade ao útil, portanto confere valor de verdade a uma teoria, a partir de resultados práticos; nesse sentido, a educação torna-se, em grande parte, a promotora $\mathrm{e}$ avaliadora dos resultados e da verdade de uma filosofia. Ora, talvez, mutatis mutandis, seja isso que inspire a crença de Adroaldo na Educação Física como projeto pedagógico".

Por sua vez, o último participante do debate, Hugo Lovisolo, da UGF, posiciona-se de modo inverso ao de Guiraldelli, navegando justamente entre os pontos conflitantes do confronto entre os textos de Gaya e de Taffarel e Escobar.
Para Lovisolo, o trabalho dessas autoras é "prepotente, desrespeitoso e pretensioso" desde seus principais enunciados. Comentando um deles, o de subtítulo "Um exemplo de simplismo intelectual", enfatiza Lovisolo:

"Devemos ir por aí atacando os
simples ingênuos? Ainda mais,
penso que o artigo das
professoras Taffarel e Escobar
pretende-se colocar com o
marxismo e com as posições
emancipatórias na Educação
Física; joga pedra contra o
próprio telhado, um telhado de
vidro, frágil e construído com
u m a 1 i n g u a g e m
desnecessariamente agressiva.
Há, talvez, demasiada paixão
em suas palavras. Por último. considero que as críticas fazem perguntas que escapam ao teor e objetivos do artigo e criticam o autor por não tratar temas e questões que dele estão distantes".

Lovisolo, por outro lado, propõe-se a defender o artigo de Gaya em suas linhas gerais, declarando que "o que nos une é mais significativo do que aquilo que nos separa", porém estende-se igualmente na revisão crítica das posições de Taffarel e Escobar, por soarem "desproporcionais e desmedidas". Com esse propósito, ele diz que "os argumentos das citações são tomados como verdades absolutas, sem referência com os dados da realidade e sem interpretar os argumentos das citações nos seus respectivos contextos históricos (as críticas acusam o professor Gaya de fazer exatamente isso)". 
Digressões à parte quanto a alguns deslizes analíticos de Gaya e ao uso intempestivo da teorização marxista por Taffarel e Escobar, Lovisolo prefere avançar por contra-exemplos até alcançar conclusões:

"A definição de uma área ou campo disciplinar não pode ser rigorosa (...) O mal- entendido resulta, penso, também no modo de exposição de Gaya, quando pretende que deva existir apenas uma definição do Direito, da Engenharia, da Educação Física ou de qualquer outro campo disciplinar (...) A multiplicidade de propostas pode coexistir, embora com conflitos, se a tolerância, o respeito mútuo e o acordo sobre os padrões que regem as atividades científica e profissional retornarem-se valores orientadores da participação (...) Espero, também, que a pirotécnica que caracteriza as polêmicas não ocupe o lugar dos problemas substantivos".

Com a retomada do que julgo essencial nos textos do intencionado debate e respondendo a um convite dos editores da revista Movimento; pretendo, neste ensaio, desentravar a polêmica criando posições que tragam à luz novas contribuições. Reexaminarei, entretanto, apenas os textos de Gaya e de Taffarel e Escobar, uma vez que c o n c ordo com a s intervenções de Bracht, Santin, Guiraldelli e Lovisolo. Esta continuação, a meu ver, necessita de novo repasse das formas adotadas pelos dois primeiros textos e

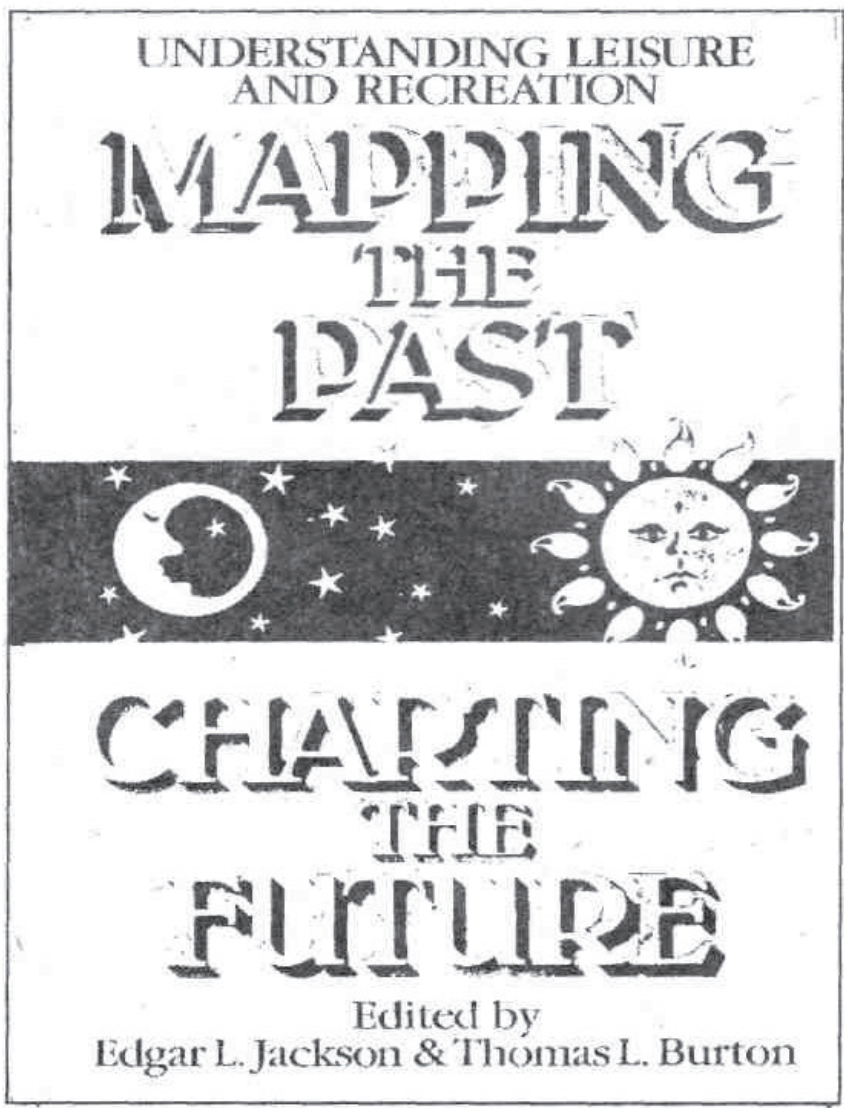


Em contas finais, as proposições de Gaya seguem um formato que gerou uma solução no interior da própria Educação Física. Com isso a opção final privilegiou a mediação dos conhecimentos envolvendo as práticas corporais em lugar de uma identidade científica própria. Se há dúvidas quanto à capacidade do educador físico em se comportar como preconiza Gaya, então o debate desloca-se da adequação epistemológica para o sentido e significado da Educação Física atual, ou melhor, para o conteúdo. De qualquer modo, não há como desautorizar a validade de um debate sobre as questões reconstruídas por Gaya, principalmente se forem admitidas no futuro como um ponto de partida.

\section{REVISITANDO \\ TAFFAREL \\ E ESCOBAR}

A meu ver, a rejeição radical das abordagens de Gaya no segundo texto refere-se ao modo escolhido de tratar conhecimentos por dogmatismos excludentes, no c a so, exercido arbitrariamente em nome do $\mathrm{m}$ a r x i s mo. Co mo anteriormente apontado, não houve um confronto com a argumentação de Gaya simplesmente porque as críticas de Taffarel e Escobar estão referenciadas a um corpo teórico autosuficiente, que renega a própria concepção da dialética originária de Marx.

Essa versão vinda do leninismo e do estalinismo não admite discussões fora de sua coerência interna. Sendo, portanto, autoreflexiva a corrente a qual explicitamente Taffarel e Escobar estão

\section{A filosofia e a ciência têm \\ difícil convivência}

com as crenças

religiosas, políticas e

ideológicas e,

freqüentemente, são

submetidas a controle e falseamentos.

engajadas, participam de debates, congressos e outros eventos acadêmicos, sobretudo para desconstruir, sistematicamente, posições diferentes das suas, como também divulgar a ideologia que dá sentido às suas ações. Isso se repetiu no caso de Gaya, dissolvendo o desenvolvimento inicial e até mesmo a própria discussão.

$\mathrm{Com}$ o s s e procedimento tem paralisado, no meu entender, o debate em vários âmbitos da Educação Física brasileira, cabe analisar, adicionalmente, o desvio provocado por Taffarel e Escobar. Efetivamente, tenho $\mathrm{t}$ e $\mathrm{st}$ e $\mathrm{m} \mathrm{unh}$ a d o a s obrevivên cia d e comportamentos não-acadêmicos similares em eventos da Educação Física desde os anos 70 e atribuo a tolerância de meus pares a duas razões:

(a) prolongamento das lutas da Universidade Brasileira contra a ditadura militar, que após a redemocratização do país, em 1985, deslocaram-se para outras frentes em favor da justiça social e por meio de nichos grupais, entre os quais e definiram correntes libertárias de Educação Física;

(b) exigência de comportamento moral, partindo de certos líderes acadêmicos ou profissionais da Educação Física e envolvendo a comunidade de professores com relação à corrupção e à violência, que caracterizam o país, e à necessária conclamação em espaços disponíveis, i n c l u ind o-s e a s oportunidades de debate acadêmico.

Assim, se de um lado há legitimidade em a e b num país como o Brasil, constantemente assolado por conflitos sociais de extrema importância, por outro lado violentam-se os saberes filosóficos e científicos pela tentativa de priorizar, de modo absoluto, princípios libertários. Deste ponto de vista, interpreto o desconforto que perpassam os textos de Bracht e Santin a o $1 \mathrm{idarem}$ com o antagonismo radical de Taffarel e Escobar. Daí se poderia explicar o distanciamento d e Guiraldelli num debate que se inicia por argumentos e se desdobra por acusações. Daí também a origem da perplexidade acadêmica de Lovisolo, que acaba por mobilizar consciências em prol do respeito mútuo e de problemas substantivos.

Um outro aspecto a assinalar quanto ao dilema de tolerar dogmatismos e denúncias, para manter posições morais adequadas ao exercício intelectual, ou re a g i r u a n to a o abastardamento do saber concerne ao risco de se banalizar a exclusão e a intimidação acadêmica, como conseqüência do tom inqui-sitorial de certos grupos.

A s c e r te z a s absolutis-tas de Taffarel e Escobar parecem-me um exemplo desse risco, e, para demonstrar tal 
assertiva, permito-me invocar a história. Efetivamente, os filósofos e depois os cientistas sempre foram alvo de intimidações pelos poderes, a não ser quando os saberes estão em posição de dominação, como nos ensinou Foucault. $\mathrm{Na}$ Idade Média européia, por exemplo, a Igreja impôs a doutrina do credo ut intelligan (creio e portanto posso compreender), colocando a fé como prérequisito do conhecimento. $\mathrm{O}$ resultado disso foi a satanização dos incrédulos e inovadores, redundando no aparecimento da Inquisição e da denúncia legitimada pelo poder e clesiástico. Resumindo, todos aqueles que não compartilhavam da fé cristã, e posteriormente da fé católica, eram taxados como inimigos, mesmo que não o fossem.

Conseqüentemente, a "sucata idealista" de Taffarel e Escobar" tem precedentes sintomáticos, e por isso Gaya tornou-se um "inimigo", sendo rejeitado sem que fosse discutido o mérito de suas proposições. Um reforço a essa hipótese surge quando levamos em consideração o fato de que intelectuais, quando discordam das idéias daqueles que se autointitulam "progressistas" no âmbito da Educação Física b r a sile i ra, s ã o cos tumeiramente estigmatizados de "conservadores", "de direita", "representantes da classe dominante" ou "alienados".

$\mathrm{U}$ m ex e m p 10 histórico do tipo de intimidação ora cogitado encontra-se no âmbito da própria ideologia professada por Taffarel e Escobar, o que pode ser verificado numa das fontes usadas por essas autoras: o livro de Bottomore publicado em primeira edição de $1983^{5}$. Entre 1948 e 1953, na antiga União Soviética, um dos auxiliares diretos de Stalin, Trofim Lysenko, também conhecido como "cientista proletário", liderou um movimento de purificação ideológica dos cientistas em exercício nas áreas de pesquisa, principalmente na genética e na agronomia, que se aprestavam melhor aos princípios marxistas. Os resultados da submissão de dados científicos a crenças s e m com provaçõ es experimentais foram nefastos e, até hoje, repercutem na produção agrícola da Rússia e países associados.

Algo similar ocorreu com o desporto das nações então socialistas do leste europeu, desde o fim da Segunda Guerra Mundial até a década de 1980. Segundo Foldesi ${ }^{6}$, socióloga que participou diretamente da direção desportiva na Hungria como membro do Partido Comunista, os excelentes resultados no desporto de alto nível obtidos naquele grupo de países foram produto de um processo seletivo de atletas e de treinamento promovido e controlado por laboratórios especializados. Porém, como tais soluções não afinavam ideologicamente com a indiferença da maior parte da população, excetuando-se nesse particular a Alemanha Oriental, com respeito à prática desportiva de massa, os governos simplesmente intimidavam os cientistas do desporto e os acadêmicos da Educação Física para que a apatia popular não fosse revelada. Com a queda do socialismo real, no final dos anos 80, o desporto do leste europeu mostrou, de imediato, sua verdadeira face, idêntica ao capitalismo quanto à busca desumana de resultados e sem qualquer limite ético.

Em suma, esses exemplos apenas ilustram o que se constata desde Sócrates, Giordano Bruno, Galileu, Einstein, Walter Benjamin e outros: a filosofia e a ciência têm difícil convivência com as crenças religiosas, políticas e i d e o l ó g i c a s e, freqüentemente, são submetidas a controle e falseamentos.

Delimitar essa tensão não tem aqui o significado de atribuir às ciências e à filosofia um ideal de pureza e inocência, mas apenas de revelar o equívoco de se punir apressadamente Gaya por seus ímpetos e pis temológicos, na suposição de que ele foi contaminado por colegas e instituições estrangeiras.

\section{REABILITANDO O DEBATE}

Admitindo que assumo o risco de ser "denunciado", como foi Gaya, penso que o debate deve ser reabilitado a partir do primeiro texto, pois é também ético abrir espaços para novos pensadores da Educação Física brasileira do mesmo modo que se promova uma moral social, como quis Marx e como querem Taffarel e Es-cobar. Deixando os textos "paralisados", sem um $\mathrm{d}$ e s e n c a d e a m e n t o participativo, perde a academia e perde o fazer político, que necessita de críticos 
quando realmente visa ao bem comum.

Com essa proposta em mente, sugiro que não nos deixemos impregnar pelo sofisma da "sucata idealista" e retomemos os autores de qualquer origem e índole, pois cabe a nós, como em qualquer trabalho acadêmico sério, digeri-los de acordo com nossos interesses de investigação. Se retornamos a Gaya, minha contribuição nessa oportunidade deslocase para o conteúdo, cujo exame parece-me cabível através de comparações com estudos, estrangeiros. De fato, a pergunta do que é e para onde tende a Educação Física tem tido, ultimamente, atenções significativas por parte de acadêmicos e de líderes dessa área profissional e de atividades físicas afins ou coincidentes, como o desporto, o lazer e a recreação.

A 1 é $\mathrm{m}$ d o s congressos de final de milênio, que têm estabelecido perspectivas para o século 21, já estão disponíveis obras que tentam sintetizar a recente produção acadêmica internacional, naturalmente esparsa e fragmentada quanto às tendências das práticas físicas. Esse é o caso dos livros editados por Landry, da Universidade Laval (Canadá), em 19917; por Oja e Telama, da Universidade de Jyvaskila (Finlândia), também em 1991; e por Jackson e Burton, da Universidade de Alberta (Canadá), em 1989 , respectivamente centrados no desporto, nas atividades físicas em geral (Desporto para todos, promoção de saúde, educação física, etc.) e nas atividades de lazer.
Em conclusão, o conhecimento

internacional da

Educação Física

aparenta estar em pleno

processo de busca de

uma nova identidade

para o setor, o que, nesse

caso, confere com a

problematização

de Gaya.

$\mathrm{Nessas}$ obras, observa-se, em primeiro lugar, que às preocupações internacionais no universo das práticas físicas estão voltadas para a promoção da saúde e, sobretudo, para as mudanças sócio-culturais externas à Educação Física, ao desporto e ao lazer. Em outras palavras, tais tendências de estudos e pesquisas sugerem um sentido inverso ao adotado por Gaya ao propor um modelo de pedagogia como intervenção profissional. $\mathrm{Ou}$ seja: enquanto as revisões internacionais apontam como base de intervenções as necessidades e as aspirações dos destinatários, o modelo d e Gay a revê o a perfeiçoamento da intervenção por meio dos professores.

$\mathrm{Um}$ retorno à $\mathrm{s}$ contribuições de Bracht e Guiraldelli mostra que seus comentários aproximam-se do contraste "entre a intervenção intrínseca (Gaya) e a intervenção definida por demandas externas. Ao passo que $\mathrm{Bracht}$ enfatizou a distinção entre ser e dever ser, cuja transposição depende do "curso necessário da história" dentro de intercâmbios dialéticos, Guiral-delli valorizou os resultados práticos a serem obtidos por uma Educação Física pragmática. Isso teria, no m e u entender, um significado de dever ser da Educação Física para a solução defendida por Gaya, que careceria, no entanto, de uma visão do ser, dificultando a transposição almejada por Bracht é o alcance utilitário antevisto por Guiraldelli.

Nesse particular, posso contribuir no esclarecimento da aqui suposta carência de Gaya, por meio de um estudo publicado no exterior ${ }^{10} \mathrm{e}$ outro no Brasil", ambos relacionados ao perfil dos intelectuais brasileiros que, por comparações históricas com seus homólogos franceses e alemães, exibiriam uma preferência, por vezes desmedida, pelo dever ser quando do trato de intervenções sociais. Isso corresponderia a um esforço maior na transmissão do que na recepção, ou ainda numa atenção preferencial sobre reformas em lugar das s ituaçõ es a s e rem reformadas.

A idiossincrasia do dever ser também foi por mim identificada em pesquisa realizada em $1985^{12}$ envolvendo líderes profissionais e acadêmicos da América do Sul pertencentes à Educação Física, desporto e recreação. Nesse trabalho produzido para a Universidade do Desporto de Colônia (A lemanha), foram evidenciadas dificuldades em discernir o status das práticas físicas com base na cultura das diferentes populações dó 
continente, já que a maior parte dos respondentes era fluente quanto à forma como deveria ser a Educação Física em seus países, mas raramente conseguiam relatar como ela transcorria em realidades locais.

C a r ên c i a d e investigações sobre esse tema à parte ${ }^{13}$, há, então, indícios que reforçam a hipótese de que os educadores físicos brasileiros, acrescidos possivelmente por seus colegas sul-americanos e de outros continentes, têm dificuldades na transposição do dever ser para o ser, o que explicaria, em tese, o apego a soluções tradicionais, às vezes distantes da c o m p r e e n s ã o d o s destinatários. Essa tendência é justamente a que se está modificando no âmbito internacional. Em Jackson e Burton, por exemplo, há dados significativos a respeito de uma inversão de expecta- tivas: num levantamento preliminar ao planejamento do livro, 143 intelectuais de destaque na área de lazer e recreação de diversos países foram consultados quanto aos temas que deveriam ser abordados, por resolverem questões presentes e futuras; ao final, os resultados ind i c a r a que a s preferências concentravamse no conhecimento das atitudes dos destinatários das atividades, tanto quanto nas análises de demanda, no papel do turismo e dos locais de lazer (principalmente capacidade de atendimento e uso de meios aquáticos) e na caracterização dos grupos especiais (terceira idade, de-, ficientes físicos, marginalizados sociais, etc,), alcançando entre $85,3 \%$ e $39,9 \%$ das opções ${ }^{14}$.

Também nesses resultados, o item "conceitos e teorias", que corresponde na pre- sente análise às tradições do setor, aparece em $9^{\circ}$ lugar, assinalado por $39,9 \%$ dos respondentes. De resto, os demais itens abrangeram interesses de gestão, de atividade profissional, de disciplinas auxiliares e de intervenção na comunidade.

De certo modo, esse r e s u l t a d o n ão é surpreendente, dada à tradição dos estudos de lazer serem voltados às mais das vezes para os destinatários. $\mathrm{O}$ que é novo, no caso, é da tendência repetir-se no desporto, uma área tradicionalmente vinculada à intervenção pedagógica e ao desenvolvimento individual, grupal, comunitário e institucional por via de modelos e paradigmas. Assim, na extensa revisão de Landry, que reuniu 72 textos, há uma dominância de $36,1 \%$ relacionados aos significados sócioculturais do desporto na atu-

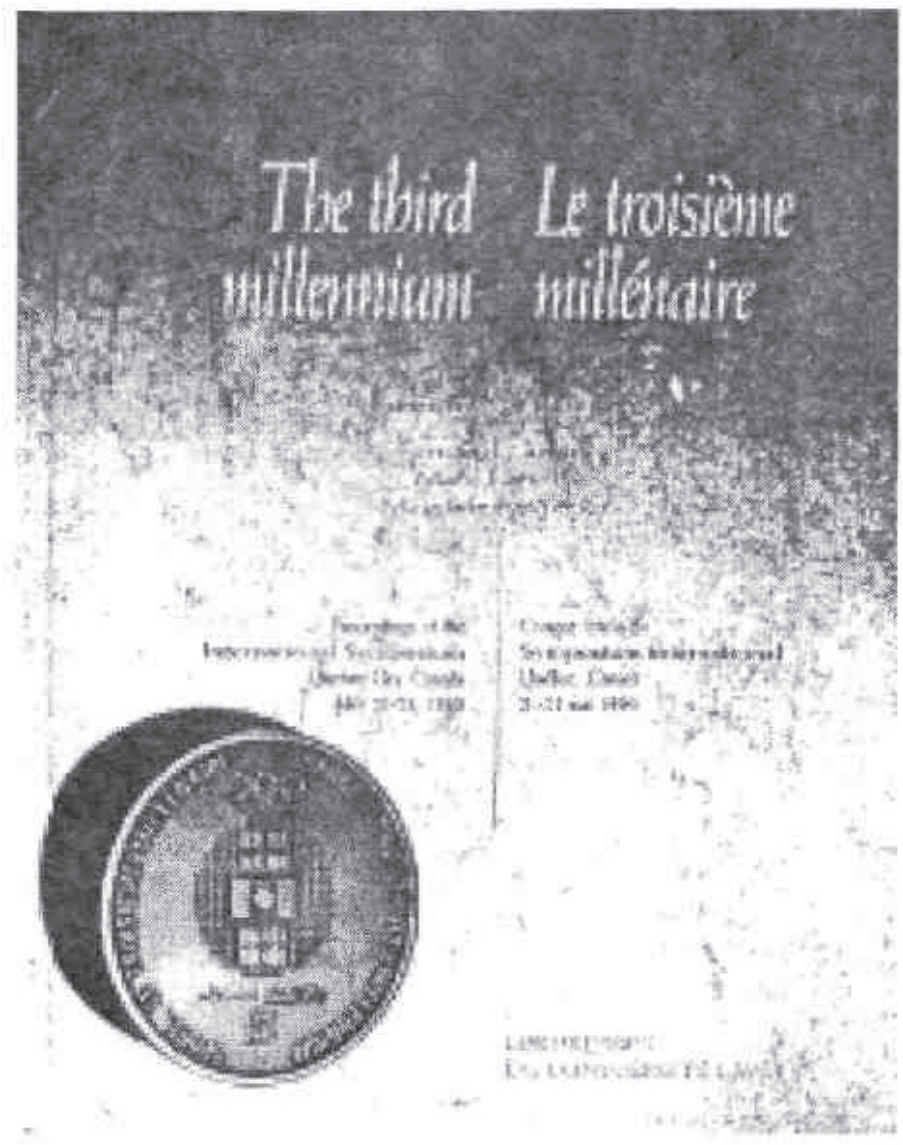


alidade. Os estudos tradicionais incluíram 33,3\% dos autores, enquanto $16,6 \%$ dedicaram-se a estudos históricos e filosóficos, e $13,8 \%$ a revisõ es interpretativas sociológic as e econômicas.

Acrescente-se, por ser também significativo, que as visões sócio-culturais encontradas em Landry obra, alias, patrocinada pelo Comitê Internacional Olímpico, uma entidade notabilizada por seu conservadorismo fixaramse, preferencialmente, no impacto das mudanças culturais detectadas nos avanços e retrocessos da pósmodernida-de, que abrangem hoje tanto o mundo desenvolvido como as regiões pobres do Terceiro Mundo. Nesse concerto de relações, os estudos concentraram-se na televisão e demais tecnologias de c o muni c ação, c o mo igualmente nos grupos sociais peculiares (mulheres, desempregados, idosos, adolescentes, obesos, etc), que estão transformando a recepção do desporto, reinventando suas práticas e relativizando as intervenções tradicionais $^{15}$.

Com respeito ao livro de Oja e Telama, 110 autores escreveram 75 textos, dos quais a maioria versa sobre a temática da saúde, comportando $37,3 \%$ das colaborações. Por seu turno, os trabalhos tra-dicionais situaram-se em 22,6\% das opções, com os temas culturais atingindo $17,3 \% \mathrm{e}$ os de gestão e economia marcando $22,6 \%$. Cotejando esse perfil com as constatações obtidas em Landry e em Jackson e Burton, comprova-se que a Educação Física (ora incluindo o desporto e o lazer) inclina-se a ter seus conteúdos conhecimento: práticas físicas, cultura e saúde, com a primeira enfocando modos de intervenção e as duas últimas demandas e repercussões de tais práticas junto aos destinatários.

Ademais, a natureza dos estudos e investigações nas áreas de cultura e saúde indicam que a base para as intervenções são os chamados grupos-alvo, de caracterização típica, mas influenciados por manifestações culturais diversificadas e instáveis de origem situacional, local, regional e até mesmo globa $^{16}$. Nesse contexto, é possível a dmitir, adicionalmente, que as ações autônomas dos destinatários tendem a se associar com as intervenções de formação e de proteção terapêutica providas por profissionais e instituições. Essa tese pode s e r c o n firm a d a preliminarmente acompanhando-se a evolução recente dos congressos da Associação Internacional de Escolas Superiores de Educação Física-AIESEP.

O conhecimento corrente sobre a AIESEP diz que se trata de uma entidade internacional com tradição centrada na Educação Física escolar e propósitos relacionados à preservação dos cânones educacionais nas atividades físicas orientadas. A partir do Congresso Mundial de Berlim, em 1994, a AIESEP tem procurado incentivar o debate sobre a redefinição da Educação Física em que pese seu papel necessariamente conservador em meio às $\mathrm{dem}$ a is entidades internacionais do setor.

Nessas circunstâncias, o procedimento adotado tem conferencistas principais (keynote speakers) capazes de revisar a Educação Física diante dos desafios gerados pelas mudanças sociais. Isso ocorreu em Berlim, quando dos oito keynotes c onvidados, seis examinaram possíveis e novas contextualizações para a Educação Física. No ano seguinte, o congresso da AIESEP deslocou-se para Israel, e, nessa oportunidade, dos 13 keynotes, seis enfocaram temáticas da cultura, sociedade e saúde. Ó próximo congresso está programado para acontecer no Rio de Janeiro em 1997, tendo como tema central "Qualidade de Vida e Cultura", por sugestão da Universidade Gama Filho, organizadora do evento.

Em conclusão, o conhecimento internacional da Educação Física aparenta estar em pleno processo de busca de uma nova identidade para o setor, o que, nesse caso, confere com a proble-matização de Gaya. A distinção, contudo, entre uma e outra parte reside no fato de que Gaya solicita do professor uma postura normativa, e a tendência internacional dominante converge para uma Educação Física segmentada, $r$ e g i o n a li zad a e culturalmente apropriada. Haveria alguma forma de combinar as duas opções, ou ambas são incompatíveis entre si? Há possibilidades, diante de tantas incertezas no Brasil e no exterior, de responder, no presente estágio, à pergunta do que é a Educação Física?

\section{NOTAS \\ ${ }^{1}$ Ver LEE, R. (Editor) -Para abrir as ciências sociais: relatório da Comissão Gulbekian sobre a}


reestruturação das Ciências Sociais". Publicações EuropaAmérica, Lisboa, 1996, p. 101130.

${ }^{2}$ Ibidem, p. 103

${ }^{3}$ Com relação às dificuldades para a análise das mudanças cul turais da atualidade, consulte-se IANNI, O. Teorias da globali zação, Civilização Brasileira: Rio de Janeiro, 1995. p. 13-24.

${ }^{4}$ Constate-se em BACHER, CA Foundations of Physical Education, The C.V. Mosby Co: Saint Louis, 1968. p. 150-182.

${ }^{5}$ BOTTOMORE, T. A dictionary of marxist thought, $\mathrm{H} \quad \mathrm{a} \quad \mathrm{r} \quad \mathrm{v} \quad \mathrm{a} \quad \mathrm{r} \quad \mathrm{d}$ University Press: Cambridge, 1983.p. 194-195.

${ }^{6}$ FOLDESI, G.S. From mass sport to the sport for all movement in the socialist countries in Eastern Europe", World Congress on Fitness, Nutrition and Sport for All, Chi cago, May 1990.

${ }^{7}$ LANDRY, F. (Editor) Sport: the third miliennium, Les $\begin{array}{llllllllll} & \mathrm{r} & \mathrm{e} & \mathrm{s} & \mathrm{s} & \mathrm{e} & \mathrm{s}\end{array}$ de 1'Université Lavai, Quebec Sainte-Foy, 1991.
OJA, P. e TELAMA, R. Sport for all, Elsevier Science Publishers: Amsterdam, 1991.

9 JACKSON, E.L. e BURTON, T.L. Understahding leisure and recreation mapping the past: charting the future", Venture Publishing Inc.: Pennsilvania, 1989.

${ }^{10}$ DA COSTA, L.P. Intelectuais Franceses e Brasileiros: verso e reverso". CARAVELLE-Cahiers du Monde Hispanique et LusoBresilien, ${ }^{a}$ 51,1991, Toulouse, p. 161-170.

${ }^{11}$ DA COSTA, L.P. A transfigu ração da história pela cultura do dever-ser na Alemanha e no Bra sil. Memória e Cultura, vol. 3, rial, 1993, Rio de Janeiro.

${ }^{12}$ DA COSTA, L.P. Images of sport in South America. Sport University of Cologne, $75^{\text {th }}$ Anniversary Congress,

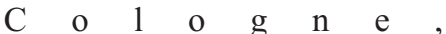
November 1995.

${ }^{13}$ Verifique-se essa carência de investigações em OTANEZ, J.D. Las escuelas de Educación Física en Latinoamérica: estúdio comparativo. Ediciones Sado Córdoba Argentina, 1994, p. 203-210.

14 JACKSON e BURTON (1989), Op. Cit., pp. 3-28.

${ }^{15}$ Veja-se em DA COSTA, L.P. O papel central da cultura nas mudanças e desafios atuais da Educação Física e do desporto". In: Ensaios sobre Educação Fi sica, Esporte e Lazer, RE ZENDE, H.G. e VOTRE, S.J. (organizadores), SBDEF/UGF, 1994, Rio de Janeiro, p. 148165.

${ }^{16}$ Consultar POWELL, K.E. et allii Progress and problems in the promotion of physical activity. In: Sport for All, Oja, P. e Telama, R. (eds.), Op. Cit., pp. 55-73.

\section{UNITERMOS}

Educação Física - Ciências Filosofia

* Lamartine P. da Costa é Doutor em Filosofia e Professor da UGF-Rio de Janeiro/RJ. 